\title{
Case Report: Investigation and molecular genetic diagnosis of familial hypomagnesaemia: a case report [version 1; peer
} review: 1 approved, 3 approved with reservations]

Jamie Willows', Maryam Al Badi², Chloe Richardson³, Noel Edwards'3, Sarah Rice ${ }^{3}$, John A. Sayer (iD) 1,3,4

\footnotetext{
${ }^{1}$ Renal Services, The Newcastle upon Tybe Hospitals NHS Foundation Trust, Newcastle upon Tyne, NE7 7DN, UK ${ }^{2}$ National Diabetes and Endocrine Center, Royal Hospital, Ministry of Health,, Muscat, Oman

3Institute of Genetic Medicine, Newcastle University, Central Parkway, Newcastle upon Tyne, NE1 3BZ, UK

${ }^{4}$ NIHR Newcastle Biomedical Research Centre, Newcastle University, Newcastle upon Tyne, NE4 5PL, UK
}

V1 First published: 15 May 2019, 8:666

https://doi.org/10.12688/f1000research.19006.1

Latest published: 05 Dec 2019, 8:666

https://doi.org/10.12688/f1000research.19006.2

\section{Abstract}

Genetic mutations causing familial hypomagnesaemia syndromes are well-recognised. Affected patients can present with severe symptoms of hypomagnesaemia, such as seizures or cardiac arrhythmia. We report an affected child, from a consanguineous family, who presented in the first weeks of life with seizures secondary to hypomagnesaemia, without other associated clinical features. We performed whole exome sequencing in the affected child and segregation analysis within the family, which revealed a novel homozygous missense mutation in TRPM6, which was confirmed as a heterozygous allele in both parents and two younger siblings who had transient hypomagnesaemia. Using in silico modelling, we provide evidence that the missense variant p.(K1098E) in TRPM6 is pathogenic, as it disrupts stabilising TRP domain interactions. Management of familial hypomagnesaemia relies on prompt recognition, early magnesium replacement and lifelong monitoring.

\section{Keywords} hypomagnesaemia, with secondary hypocalcaemia, TRPM6, molecular genetics

\section{Open Peer Review \\ Approval Status

$\begin{array}{llll}1 & 2 & 3 & 4\end{array}$ \\ version 2 \\ (revision) \\ 05 Dec 2019 \\ version 1 \\ 15 May 2019

$\checkmark$

$\begin{array}{cc}? & \\ \text { view } & \text { view } \\ ? & ? \\ \text { view } & \text { view }\end{array}$

1. Karl Peter Schlingmann, University Children's Hospital, Münster, Germany

2. Lilia Romdhane ID, University of Tunis EI Manar, Tunis, Tunisia

University of Carthage, Zarzouna, Tunisia

3. Abhijit Dixit iD, Nottingham University Hospitals NHS Trust, Nottingham, UK

4. Na Zhu ID, Columbia University Medical Center, Columbia, USA

Any reports and responses or comments on the article can be found at the end of the article. 
Corresponding author: John A. Sayer (john.sayer@ncl.ac.uk)

Author roles: Willows J: Writing - Review \& Editing; Al Badi M: Investigation, Methodology, Writing - Original Draft Preparation; Richardson C: Investigation, Methodology, Writing - Original Draft Preparation; Edwards N: Investigation, Methodology, Software, Writing - Original Draft Preparation; Rice S: Investigation, Methodology, Resources, Software; Sayer JA: Funding Acquisition, Investigation, Methodology, Project Administration, Supervision, Validation, Writing - Original Draft Preparation, Writing - Review \& Editing

Competing interests: No competing interests were disclosed.

Grant information: We thank Northern Counties Kidney Research Fund (BH160804) who supported this work. The funders had no role in study design, data collection and analysis, decision to publish, or preparation of the manuscript.

Copyright: (c) 2019 Willows J et al. This is an open access article distributed under the terms of the Creative Commons Attribution License , which permits unrestricted use, distribution, and reproduction in any medium, provided the original work is properly cited.

How to cite this article: Willows J, Al Badi M, Richardson C et al. Case Report: Investigation and molecular genetic diagnosis of familial hypomagnesaemia: a case report [version 1; peer review: 1 approved, 3 approved with reservations] F1000Research 2019, 8:666 https://doi.org/10.12688/f1000research.19006.1

First published: 15 May 2019, 8:666 https://doi.org/10.12688/f1000research.19006.1 


\section{Introduction}

Homeostasis of the serum magnesium level is essential for human cellular function, and levels are maintained in the normal range by tight control of magnesium reabsorption by the kidney tubules ${ }^{1}$. Hypomagnesaemia can manifest with a range of symptoms, from tremor, muscle spasms or nystagmus through to seizures, arrhythmias and cardiac arrest. Early identification of the electrolyte abnormality is vital, as treatment with magnesium replacement is efficacious and inexpensive. Common causes of hypomagnesaemia in adults include refeeding syndrome, diarrhoea, malabsorption, alcohol abuse and medications such as proton pump inhibitors ${ }^{2,3}$. Renal magnesium wasting is indicated by an inappropriately high fractional excretion of magnesium in urine despite hypomagnesaemia, and is seen in postobstructive diuresis, the recovery phase of acute tubular necrosis, hypercalcaemia and in response to certain diuretics ${ }^{4}$. However, genetically inherited mutations that cause renal hypomagnesaemia are well-recognised, and typically present in childhood if they are secondary to autosomal recessive disorders ${ }^{5}$. Genetic forms of hypomagnesaemia should also be considered in certain clinical scenarios, such as in the presence of a positive family history of related disorders, consanguinity, or fulminant presentation.

Once a genetic cause of hypomagnesaemia is suspected, work-up can be guided by associated features and age at presentation. Though obtaining a genetic diagnosis will not alter the treatment of magnesium replacement therapy, it is vital for identifying others at risk and family counselling, and may help to guide the clinician to screen for associated phenotypic features.

\section{Case report}

We report a child from a consanguineous family (parents were second degree cousins) from Oman, who presented with seizures and hypomagnesaemia. The affected individual, a female child, presented at 20 days of age with tonic-clonic seizures. There was no history of fever or diarrhoea, and after an uncomplicated pregnancy she had been born healthy at term, without syndromic features. Serum magnesium was severely low at $0.35 \mathrm{mmol} / \mathrm{L}$ and was associated with a mild hypocalcaemia and suppressed parathyroid hormone (PTH) (Table 1). The urinary fractional excretion of magnesium was inappropriately in the normal range given the severe degree of hypomagnesaemia present, suggesting contributory renal magnesium wasting. There were no other specific clinical or biochemical features; of note peripheral oxygen saturations and capillary blood glucose levels were within normal limits. Renal ultrasound scan was normal, with no nephrocalcinosis. She was initially treated with intravenous magnesium $\left(20 \% \mathrm{MgCl}_{2} 0.1 \mathrm{mmol} / \mathrm{kg}\right.$ every 6 hours p.r.n.) and calcium replacement (10\% Calcium Gluconate $0.11 \mathrm{mmol} / \mathrm{kg}$ ). At 4 years of age she is now supported with high-dose oral magnesium supplements (magnesium sulphate $500 \mathrm{mg}$ qds) alone, and remains well with no further seizures, though she maintains a low serum magnesium level between $0.4-0.6 \mathrm{mmol} / \mathrm{L}$.

Of note, a younger sibling of the proband, also female, presented at 18 days old with abnormal eye movements in association with a complex partial seizure. Her serum magnesium was below normal limits $(0.53 \mathrm{mmol} / \mathrm{L})$, with serum calcium and PTH within the normal range (Table 1). The fractional excretion of magnesium was inappropriately high, and again renal ultrasound scan was normal and no other clinical features were noted. She was treated with intravenous magnesium replacement $(20 \%$ $\mathrm{MgCl}_{2} 0.1 \mathrm{mmol} / \mathrm{kg}$ every 6 hours p.r.n.), followed by a period of maintenance oral magnesium replacement (magnesium sulphate $300 \mathrm{mg}$ b.d.). At 2 years of age she remains well with no further seizures, and she maintains magnesium levels within the normal range without additional supplementation. A younger asymptomatic male sibling was screened with serum biochemistry ests at 1 week of age. Serum magnesium was low at $0.6 \mathrm{mmol} / \mathrm{L}$, with normal serum calcium and PTH levels (Table 1). Supplementation was not started, and by 1 year of age serum magnesium was within the normal range.

\section{Genetic investigations}

Detailed information on the techniques described below is given in the Methods section. Following informed consent, whole exome sequencing (WES) was performed in the eldest sibling, II:1 (Figure 1). Analysis using a combination of homozygosity

Table 1. Clinical and biochemical features of siblings.

\begin{tabular}{|c|c|c|c|c|c|c|c|c|}
\hline Child & $\begin{array}{l}\text { Age at } \\
\text { diagnosis / } \\
\text { screening }\end{array}$ & $\begin{array}{l}\text { Clinical } \\
\text { Presentation }\end{array}$ & $\begin{array}{l}\text { Serum } \\
\text { Magnesium at } \\
\text { presentation (NR } \\
0.65-1.1 \mathrm{mmol} / \mathrm{L})\end{array}$ & $\begin{array}{l}\text { Serum } \\
\text { calcium } \\
\text { (corrected) at } \\
\text { presentation } \\
\text { (NR 1.7-2.8 } \\
\text { mmol/L) }\end{array}$ & $\begin{array}{l}\text { Parathyroid } \\
\text { hormone } \\
\text { (NR (NR 1.6- } \\
6.9 \text { pmol/L) }\end{array}$ & $\begin{array}{l}\text { Fractional } \\
\text { Excretion of } \\
\text { Magnesium } \\
\text { (NR 2-4\%) }\end{array}$ & $\begin{array}{l}\text { Current } \\
\text { serum } \\
\text { magnesium } \\
\text { (NR 0.65-1.1 } \\
\text { mmol/L) }\end{array}$ & $\begin{array}{l}\text { Maintenance } \\
\text { Magnesium } \\
\text { supplements } \\
\text { (magnesium } \\
\text { sulphate) }\end{array}$ \\
\hline II:1 & 20 days & $\begin{array}{l}\text { Generalised } \\
\text { seizure }\end{array}$ & 0.35 & 1.38 & 1.11 & $2.1 \%$ & $\begin{array}{l}0.4-06 \text { age } 5 \\
\text { years }\end{array}$ & $500 \mathrm{mg}$ qds \\
\hline $11: 2$ & 18 days & $\begin{array}{l}\text { Complex } \\
\text { partial seizure }\end{array}$ & 0.53 & 2.62 & 5.6 & $5.5 \%$ & $\begin{array}{l}0.7-0.9 \text { aged } \\
3 \text { years }\end{array}$ & $\begin{array}{l}300 \mathrm{mg} \text { bd } \\
\text { reduced to none }\end{array}$ \\
\hline II:3 & 7 days & Asymptomatic & 0.6 & 2.60 & $\mathrm{~N} / \mathrm{A}$ & $\mathrm{N} / \mathrm{A}$ & $\begin{array}{l}0.7-1.0 \text { aged } \\
1 \text { year }\end{array}$ & None \\
\hline
\end{tabular}

NR, normal range; Fractional excretion of magnesium $(\%)=$ Urine Magnesium $\times$ Plasma Creatinine / (0.7 x Plasma Creatinine $\times$ Urine creatinine) $\times 100$ 

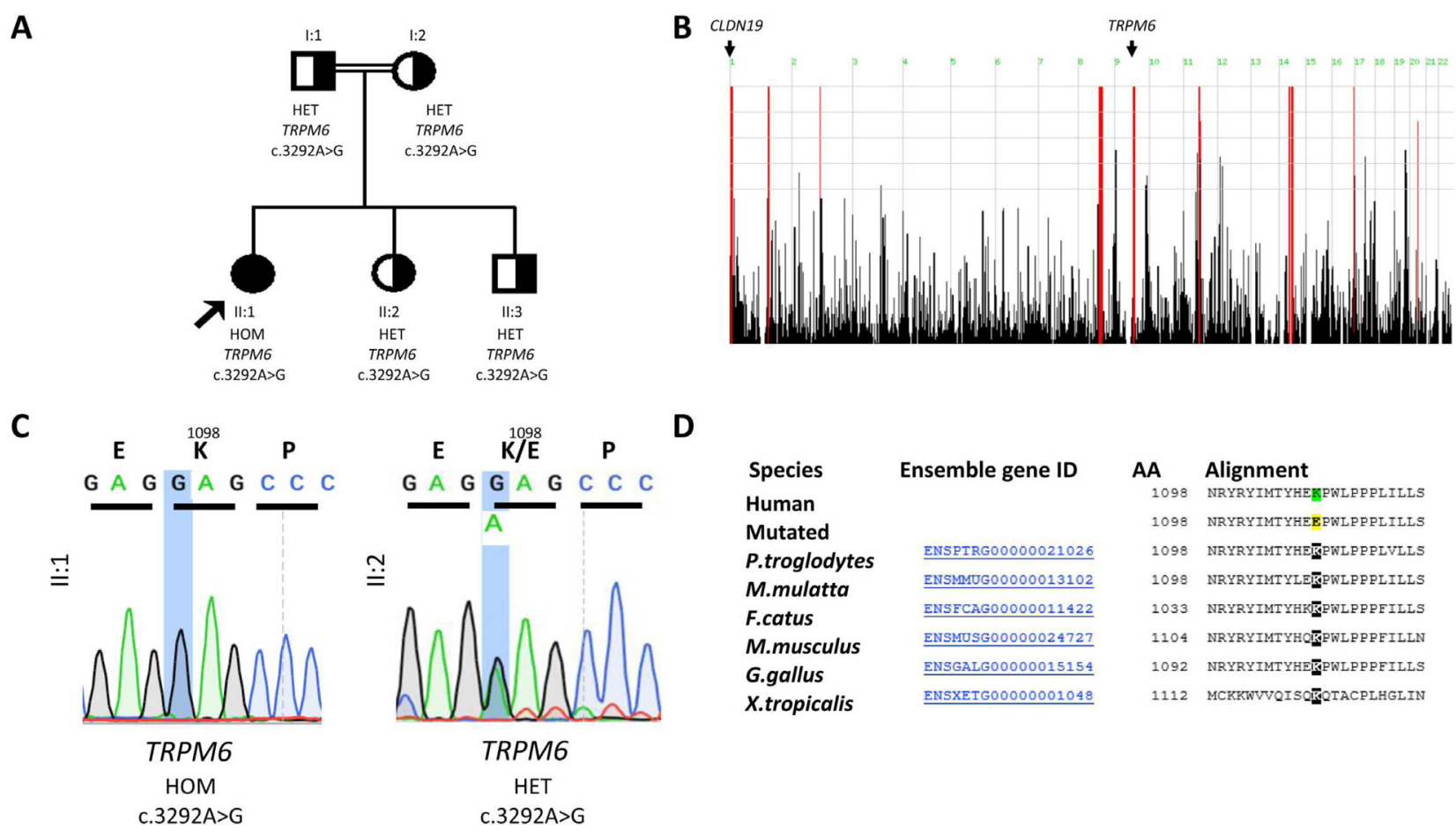

Figure 1. Identification of TRPM6 missense mutation as the cause of familial hypomagnesaemia. (A) Pedigree diagram showing proband (arrowed) who is homozygous for c.3292A>G p.(K1098E) missense mutation in TRPM6 and segregation of alleles from each parent. Parents were consanguineous (second degree cousins). (B) Homozygosity mapping across chromosomes 1-22. Red bars indicate regions of homozygosity. Candidate genes CLDN19 and TRPM6 (arrowed) are located within regions of homozygosity. (C) Chromatograms from proband (II:1) and sibling (II:2) showing TRMP6 variant in homozygous and heterozygous state, respectively. (D) Amino acid (AA) alignment showing conservation of the K1098 residue of TRPM6.

mapping and variant calling revealed a homozygous missense mutation c.3292A $>$ G, p.(K1098E) in TRPM6 within a large region of homozygosity by descent (Figure 1). The missense variant was confirmed by Sanger sequencing, and cascade screening confirmed this variant was in its heterozygous state in both parents and both mildly affected siblings. In silico tools confirmed evolutionary conservation (Figure 1) as well as the rarity and predicted pathogenicity of the variant (Table 2). Using predictive modelling of the protein structure we were able to show that the lysine residue at position 1098 is predicted to form a stabilising interaction within the TRP domain, and that the missense mutation of TRPM6 K1098 to glutamate is predicted to disrupt this interaction (Figure 2).

\section{Discussion}

As the second most abundant intracellular cation, magnesium is vital for normal cell function ${ }^{1}$. The majority of ingested magnesium load is absorbed in the distal small bowel via paracellular mechanisms, and the remainder is absorbed in the colon by transient receptor potential melastatin type 6 (TRPM6) ion channels in gut epithelium ${ }^{1}$. Serum magnesium levels make up a relatively tiny proportion of whole-body magnesium content, but needs to be kept within a narrow range to maintain neuronal, skeletal muscle and cardiac muscle cell stability. Serum magnesium homeostasis is therefore tightly regulated by reabsorption in the kidney; the majority is reabsorbed in the thick ascending limb of the loop of Henle via a paracellular route, and the 'fine-tuning' is performed in the distal convoluted tubule (DCT) via apically located TRPM6 channels.

Hypomagnesaemia is a common electrolyte disturbance, with a prevalence of $20 \%$ in hospitalised patients ${ }^{6}$. Causes in adults include inadequate intake, refeeding syndrome, renal losses, gastrointestinal losses in diarrhoea, gastrointestinal malabsorption, and medications such as proton pump inhibitors (PPIs) ${ }^{7}$. Serum magnesium levels may be requested as part of an extended biochemical panel if there is clinical concern about these risk factors, if symptoms or cardiac arrhythmia are present, or if other disturbances such as hypokalaemia or hypocalcaemia prompt the consideration of magnesium depletion. Measurement of urinary magnesium may help distinguish between gastrointestinal and renal losses. Urinary magnesium levels will be low if hypomagnesaemia is secondary to gastrointestinal losses, as the kidneys appropriately work to maximally reabsorb filtered magnesium, but raised or inappropriately normal despite low serum magnesium levels in renal magnesium wasting conditions. The majority of 
Table 2. TRPM6 variant and in silico analysis.

\begin{tabular}{|c|c|c|c|c|c|c|c|}
\hline Gene & $\begin{array}{l}\text { Nucleotide } \\
\text { variant }{ }^{*}\end{array}$ & $\begin{array}{l}\text { Predicted amino acid } \\
\text { change }\end{array}$ & $\begin{array}{l}\text { ExAC } \\
\text { frequency }\end{array}$ & gnomAD & MutationTaster & SIFT & POLYPHEN2 \\
\hline TRPM6 & c. $3292 A>G$ & p.(K1098E) & Not detected & Not detected & Disease causing & Deleterious & Possibly damaging \\
\hline
\end{tabular}

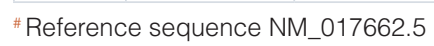
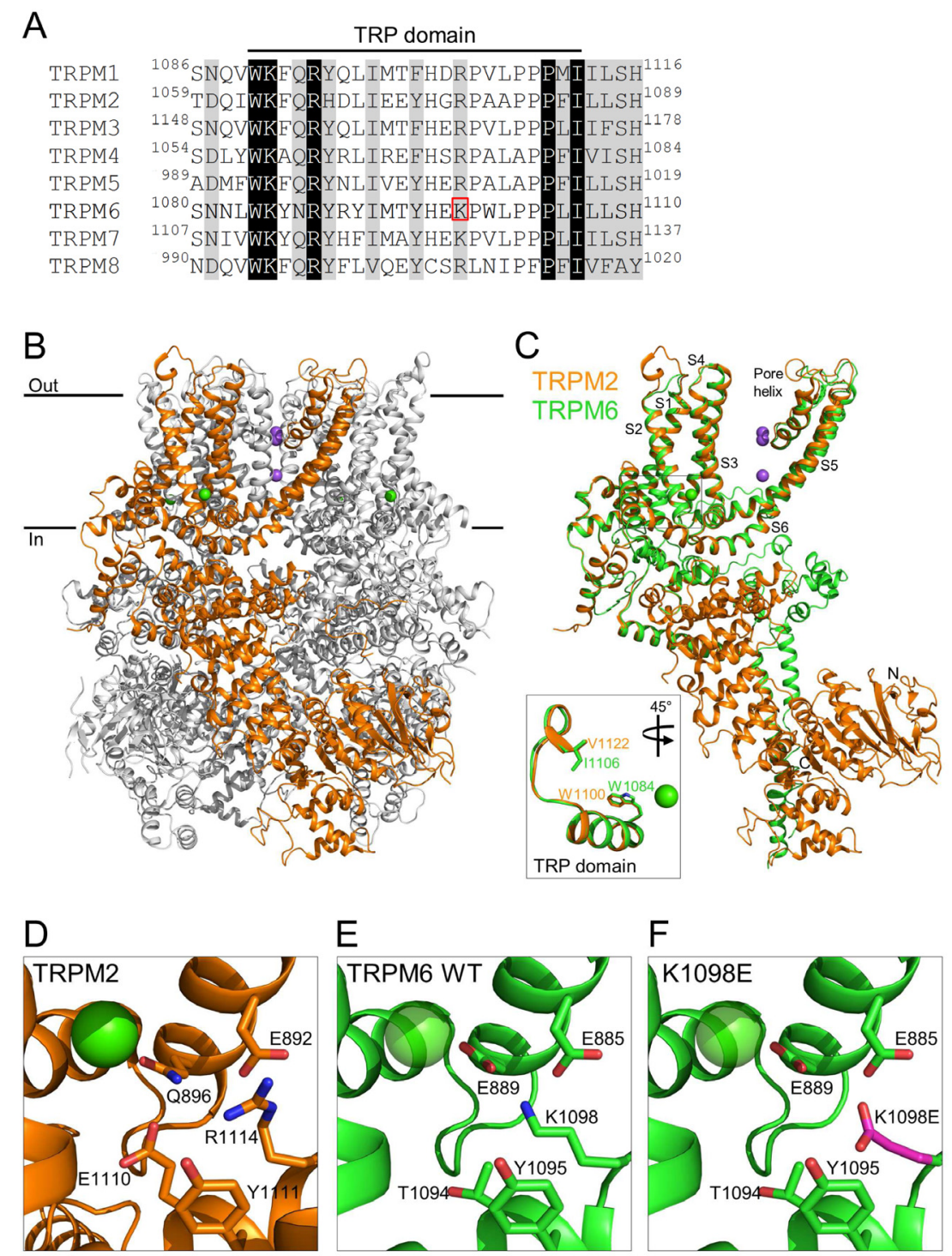

Figure 2. The TRPM6 K1098E variant affects a conserved basic residue in the TRP domain. (A) Sequence alignments of TRP domain residues from human TRPM1-TRPM8. Fully-conserved residues are highlighted in black and semi-conserved residues in grey. TRPM6 K1098 is outlined in red. (B) Cryo-EM structure of $\mathrm{Ca}^{2+}$ - and $\mathrm{Na}^{+}$-bound TRPM2 (PDB 6CO7). One monomer of the homotetrameric channel is highlighted in orange and the co-ordinated $\mathrm{Ca}^{2+}$ and $\mathrm{Na}^{+}$ions are shown as green and purple spheres, respectively. (C) Superposition of the TRPM2 monomer (orange) and TRPM6 homology model (green). The TRP domain region (box and inset), wherein the TRPM6 K1098E variant lies, is shown to highlight the predicted structural homology between TRPM6 and TRPM2. The $\mathrm{Ca}^{2+}$ ion (green sphere) is shown for orientation. (D) Close up view of TRPM2 Q896 and E1110 involved in co-ordination of the $\mathrm{Ca}^{2+}$ ion (green sphere) and R1114 (homologous to TRPM6 K1098, shown in (E)) predicted to form a stabilising interaction within the TRP domain. (F) Mutation of TRPM6 K1098 to glutamate (magenta) is predicted to disrupt stabilising TRP domain interactions. The relative position of the $\mathrm{Ca}^{2+}$ ion (green sphere) in TRPM2 is shown in $(\mathbf{E})$ and $(\mathbf{F})$ for orientation. 
renal causes of hypomagnesaemia are not genetic, such as renal losses induced by post-obstructive diuresis, the recovery phase of acute tubular necrosis, hypercalcaemia, or drugs such as loop and thiazide diuretics, cisplatin, tacrolimus and aminoglycosides.

Magnesium wasting disorders found in families have been shown to be associated with over a dozen genes ${ }^{5}$. Similar to other monogenic diseases causing renal tubule phenotypes, the study of these diseases has greatly contributed to our knowledge of the renal tubular transport proteins responsible for homeostatic and physiological functioning. Familial hypomagnesaemic renal disorders may be inherited in both autosomal dominant and recessive patterns, and the underlying genes uncovered so far all encode proteins found in the thick ascending limb of the loop of Henle or DCT. Familial hypomagnesaemias may be categorised into four groups. These include hypercalciuric hypomagnesaemias (secondary to mutations in $C L C N K B$ (Bartter syndrome type 3), CLDN16, CLDN19, CASR); Gitelman-like hypomagnesaemias (secondary to mutations in SLC12A3 (Gitelman syndrome), BSND (Bartter syndrome type 4), KCNJ10, FYXD2, HNF1B, PCBD1); mitochondrial hypomagnesaemias; (mutations in SARS2, MT-TI and Kearns-Sayre syndrome) and other hypomagnesaemias (secondary to mutations in TRPM6, CNMM2, EGF, EGFR, KCNA1, FAM111A $)^{5}$.

TRPM6 is expressed in both the colon and the DCT of the kidney, and mutations here can cause the condition known as hypomagnesaemia with secondary hypocalcaemia. There have been dozens of distinct mutations in TRPM6 associated with this condition, and different variants can cause different effects on the function of the TRPM6 transporter ${ }^{1}$. In patients with TRMP6 mutations magnesium absorption from the colon is decreased (primary intestinal hypomagnesaemia), and the DCT is unable to perform the 'fine-tuning' of magnesium reabsorption and inappropriately wastes magnesium via the urine. Due to this dual pathology, the condition can cause the most profound electrolyte wasting of the genetic hypomagnesaemias. It typically presents in the neonatal period with severe symptoms due to hypomagnesaemia and hypocalcaemia such as seizures, which are subsequently responsive to magnesium administration ${ }^{8}$. The hypocalcaemia is thought to be secondary to hypoparathyroidism, which is induced by hypomagnesaemia ${ }^{9}$. Interestingly, the observation that treatment with PPIs is associated with hypomagnesaemia has led to a proposed mechanism of PPI-induced inhibition of TRPM6 and TRPM7 channels in the gastrointestinal tract ${ }^{10}$. TRPM6 may also be downregulated in the DCT in response to cyclosporine, resulting in renal magnesium wasting ${ }^{11}$.

Treatment of all the genetic hypomagnesaemia disorders, including those caused by TRPM6 mutations, is with magnesium replacement therapy, either oral or intravenous depending on urgency and the tolerability of oral products. The major sideeffect of oral magnesium replacement is diarrhoea, which can limit treatment compliance and paradoxically cause worsening of hypomagnesaemia due to increased gastrointestinal losses. Overall the prognosis of hypomagnesaemia with secondary hypocalcaemia is excellent, and serum calcium levels normalise as serum magnesium levels improve.

Given what is known about hypomagnesaemia with secondary hypocalcaemia, our first patient presented typically, with severe symptoms and the expected biochemical profile, including low PTH. WES confirmed a homozygous missense mutation in TRPM6, and clearly the family history of consanguinity was consistent with the diagnosis of an autosomal recessive disorder. In keeping with previous case reports she did not maintain magnesium concentration in the normal range, despite high dose oral replacement. Interestingly, the second child also had severe symptoms at presentation despite ultimately proving to be heterozygous for the TRPM6 mutation. However, it can be seen that her presentation was less fulminant, without the development of tonic-clonic seizures and with milder derangement of biochemical parameters. In keeping with this less severe phenotype, she now maintains normal serum magnesium levels without supplementation. Finally, the third sibling had documented transient and asymptomatic hypomagnesaemia, which corrected by 1 year of age. These two siblings provide some evidence that a heterozygous allele in infants may lead to a transient biochemical phenotype, presumably related to the immaturity of the DCT to regulate magnesium. Adults heterozygous for TRPM6 pathogenic variants have never been reported to have abnormal serum magnesium levels ${ }^{12}$. Heterozygous Trpm6 knockout mice exhibit mild hypomagnesaemia under a normal diet, suggesting that a milder phenotype may be associated with the loss of one TRPM6 allele $^{13}$.

The location and predicted pathological effect of the missense mutation warrants further discussion. Previously described missense mutations in TRPM6 include p.(S141L) and p.(P1017R), which lead to either trafficking or gating impairment of the TRMP6 channel ${ }^{14,15}$. Additional missense mutations p.(I174R), p.(T354P) and p.(C707T) have also been reported ${ }^{16}$. Here we have taken advantage of recently published cryo-EM structures of TRPM2 $2^{17-19}$, TRPM4 ${ }^{20-23}$, TRPM $7^{24}$ and TRPM ${ }^{25}$, which suggest a conserved global architecture for TRPM family members, consistent with sequence conservation (see Extended data, Supplementary Figure 1$)^{26}$. We therefore utilised all structures to interpret the likely pathogenic effect of the TRPM6 K1098E variant (with the exception of TRPM8, due to low resolution in the homologous region ${ }^{25}$ ). TRP domain sequence analysis (Figure 2A) revealed conservation of a basic residue at the homologous position to K1098 in TRPM6, indicating an important functional role for the positively charged side-chain. Studies of TRPM6-TRPM8 suggest that positively charged residues in the TRP domain may interact with the negatively charged phosphate groups in phosphatidylinositol-4,5-bisphophate $\left(\mathrm{PIP}_{2}\right)$ to mediate channel activation ${ }^{27,28}$. Neutralisation of the positive charge by substitution with glutamine was shown to abolish channel activity in TRPM6 K1098Q ${ }^{27}$ and TRPM8 R1008Q ${ }^{28}$, although surprisingly no significant effect on channel activity was seen in the homologous TRPM7 K1125Q variant ${ }^{27}$. Moreover, the homologous TRPM4 variant (R1072Q) exhibited normal sensitivity to $\mathrm{PIP}_{2}$, arguing against this residue being involved directly 
in $\mathrm{PIP}_{2}$ binding ${ }^{29}$. Based on the available TRPM structures, we predict K1098 may mediate one of several stabilising interactions in TRPM6. In the cryo-EM structure of TRPM2 (Figure 2B), and TRPM6 homology model (Figure 2C), the TRP domain lies in close proximity to the ion conduction pathway, with mutations in this domain likely to affect channel gating. Indeed, mutation of TRP domain residues in TRPM2 (E1110) and TRPM4 (E1068) were shown to impair the binding of $\mathrm{Ca}^{2+}$ necessary for priming the channel for voltage-dependent opening $^{19,20,30}$. In TRPM2, E1110 in the TRP domain stabilises Q896 in the S2 helix (Figure 2D), correctly orienting Q896 for $\mathrm{Ca}^{2+}$-binding ${ }^{19}$. Interestingly, the glutamine residues involved in co-ordination of the $\mathrm{Ca}^{2+}$ ion in TRPM2 (Q896) and TRPM4 $\left(\mathrm{Q} 831^{20}\right)$ are conserved in all $\mathrm{Ca}^{2+}$-dependent TRPM channels (Figure 3), but are replaced by glutamate (E889) in the $\mathrm{Ca}^{2+}$-independent TRPM6 (Figure 2E). TRPM6 modelling
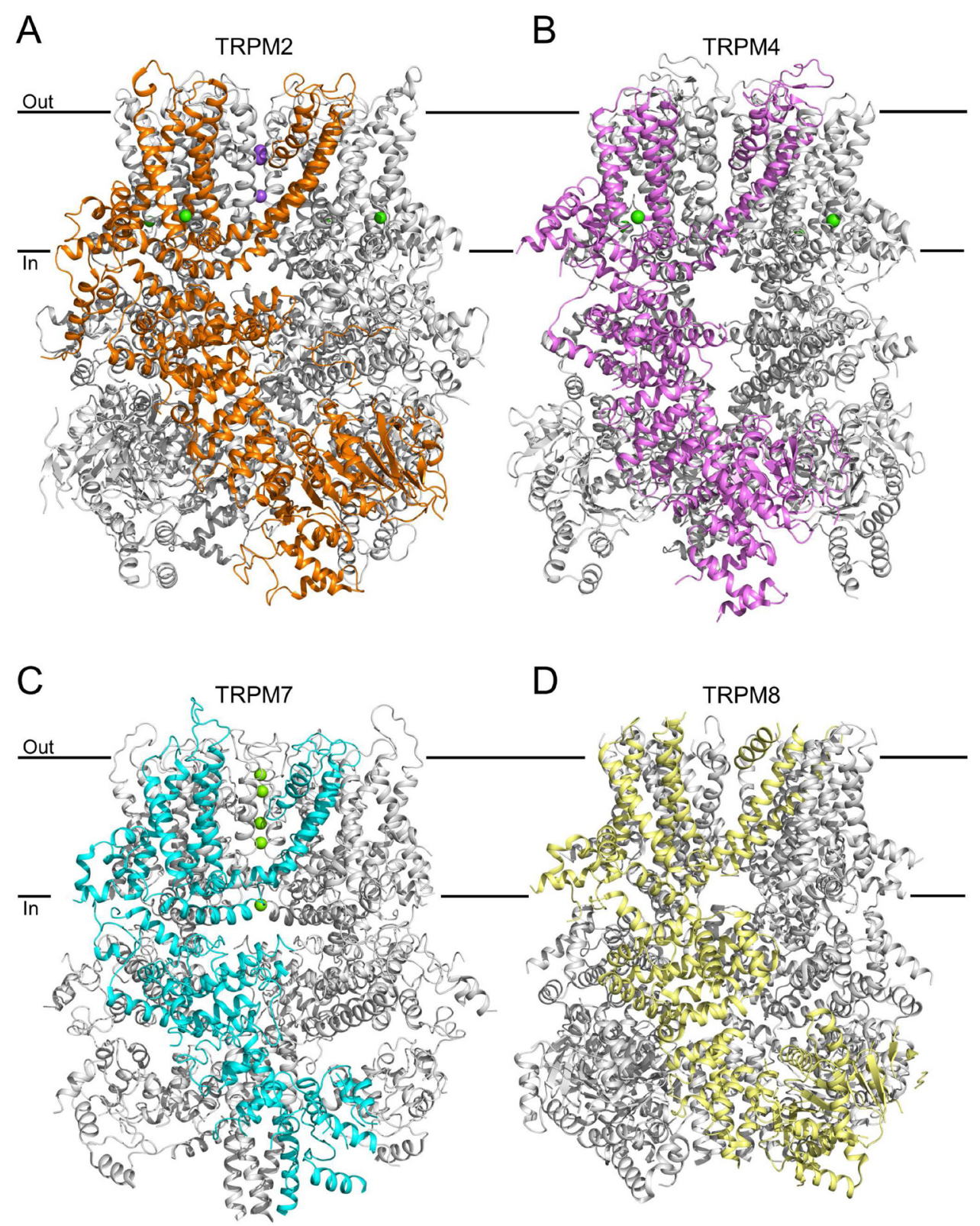

Figure 3. TRPM family members exhibit a conserved global structural architecture. Cryo-EM structures of (A) TRPM2 (PBD 6CO7), (B) TRPM4 (PDB 6BQV), (C) TRPM7 (PDB 6BWD) and (D) TRPM8 (PDB 6BPQ). One monomer of the respective tetrameric channel structure is highlighted. Spheres denote: $\mathrm{Ca}^{2+}$ (green) and $\mathrm{Na}^{+}$(purple) ions in TRPM2; $\mathrm{Ca}^{2+}$ ions (green) in TRPM4; and Mg ${ }^{2+}$ ions (green) in TRPM7. 
suggests that K1098 in the TRP domain could form stabilising interactions with E889 and E885 (equivalent to R1114 and E892 in TRPM2 ${ }^{19}$; Figure 2D) in the S2 helix (Figure 2E), thereby priming the channel for activation in a $\mathrm{Ca}^{2+}$-independent manner. Alternatively, TRPM6 K1098 may potentially serve to stabilise the TRP domain helix itself, either through a cation- $\pi$ interaction with Y1095 (Figure 2E), equivalent to that identified in the cryo-EM structure of TRPM4 between R1072 and F106922, or via interaction with the hydroxyl side-chain of T1094 (equivalent to TRPM2 E1110; Figure 2E). This latter potential interaction is analogous to that modelled between TRPM8 R1008 and E1004, whereby agonist/antagonist binding was predicted to modulate the position and intra-protein contacts of R1008 (equivalent to TRPM6 K1098), with resultant changes in the TRP domain helix effecting channel opening/closing, respectively ${ }^{31}$. Substitution of TRPM6 K1098 with the negatively charged glutamate (K1098E; Figure 2F) is predicted to be pathogenic since this change would destabilise any of the potential interactions discussed.

\section{Conclusion}

Here we provide evidence for a novel pathogenic missense mutation p.(K1098E) in TRPM6 which leads to a severe hypomagnesaemia with secondary hypocalcaemia phenotype in an affected child. In silico modelling of homologs of the TRPM channels supports an important stabilising role for this residue.

\section{Methods}

Clinical summaries were prepared and DNA samples taken from whole blood following informed and written consent. Ethical approval for this study was obtained from the National Research Ethics Service (09/H0903/36).

A DNA sample from the affected proband underwent WES, performed via GATC Biotech. A DNA library was prepared using enrichment with SureSelectXT and a human All Exon Kit. Sequencing was performed using Illumina with paired end reads of $2 \times 150$ bp with a $>30 X$ average on target coverage. Raw data was analysed via a commercial bioinformatics pipeline (GATC Eurofins), which included mapping against genomic reference sequence and detection of SNPs and InDels using GATK's Haplotype caller ${ }^{32}$. Resulting vcf files were analysed using Qiagen Ingenuity Variant analysis software (Build 5.5.20190412) (or open access equivalent VCF-Explorer 1.0)and HomozygosityMapper.

Variants in genes and segregation in other family members were confirmed using exon PCR followed by Sanger sequencing.
Human TRPM6 (UniProt accession Q9BX84) was modelled against the cryo-EM structures of TRPM2 (PDB accession 6CO7; ${ }^{19}$ ), TRPM4 (PDB 6BQV; $;^{20}$ and TRPM7 (PDB 6BWD $;^{24}$ using HHPred $^{33}$, Modeller (version 9.21) ${ }^{34}$ and I-TASSER ${ }^{35}$ software. TRPM structure figures were prepared using PyMOL 2.3 .

\section{Data availability}

Underlying data

Whole exome sequencing data available from BioProject, accession number PRJNA541906: https://identifiers.org/bioproject/ PRJNA541906.

\section{Extended data}

Figshare: Alignment of human TRPM channels 1-8 amino acid sequences. https://doi.org/10.6084/m9.figshare.806353726.

This project contains the following extended data:

\section{- Supplementary Figure 1. Alignment of human TRPM channels 1-8 amino acid sequences (UniProt accession codes Q7Z4N2, O94759, Q9HCF6, Q8TD43, Q9NZQ8, Q9BX84, Q96QT4 and Q7Z2W7, respectively), with sequences for the cryo-EM structures of $N$. vectensis $(\mathrm{Nv})$ TRPM2 (UniProt and mouse (Ms) TRPM7 (UniProt Q923J1). The position of the TRP domain, TRPM6 K1098 and homologous residues are highlighted.}

Extended data are available under the terms of the Creative Commons Attribution 4.0 International license (CC-BY 4.0).

\section{Consent}

Written informed consent was obtained from the patients' family for publication of this case report and accompanying images.

\section{Author contributions}

The project was conceived and directed by JAS. JW and JAS drafted the manuscript. All authors were involved in the revision of the draft manuscript and have agreed to the final content.

\section{Grant information}

We thank Northern Counties Kidney Research Fund (BH160804) who supported this work.

The funders had no role in study design, data collection and analysis, decision to publish, or preparation of the manuscript.
1. de Baaij JH, Hoenderop JG, Bindels RJ: Magnesium in man: implications for health and disease. Physiol Rev. 2015; 95(1): 1-46. PubMed Abstract | Publisher Full Text

2. Tong GM, Rude RK: Magnesium deficiency in critical illness. J Intensive Care Med. 2005; 20(1): 3-17.

PubMed Abstract | Publisher Full Text

3. Hess MW, Hoenderop JG, Bindels RJ, et al:: Systematic review: hypomagnesaemia induced by proton pump inhibition. Aliment Pharmacol Ther. 2012; 36(5): 405-13.

PubMed Abstract | Publisher Full Text

4. al-Ghamdi SM, Cameron EC, Sutton RA: Magnesium deficiency: pathophysiologic and clinical overview. Am J Kidney Dis. 1994; 24(5): 737-52. PubMed Abstract | Publisher Full Text

5. Viering DHHM, de Baaij JHF, Walsh SB, et al.: Genetic causes of 
hypomagnesemia, a clinical overview. Pediatr Nephrol. 2017; 32(7): 1123-35. PubMed Abstract | Publisher Full Text | Free Full Text

6. Cheungpasitporn W, Thongprayoon C, Qian Q: Dysmagnesemia in Hospitalized Patients: Prevalence and Prognostic Importance. Mayo Clin Proc. 2015; 90(8): 1001-10.

PubMed Abstract | Publisher Full Text

7. Ayuk J, Gittoes NJ: Contemporary view of the clinical relevance of magnesium homeostasis. Ann Clin Biochem. 2014; 51(Pt 2): 179-88. PubMed Abstract | Publisher Full Text

8. Paunier L, Radde IC, Kooh SW, et al:: Primary hypomagnesemia with secondary hypocalcemia in an infant. Pediatrics. 1968; 41(2): 385-402. PubMed Abstract

9. Anast CS, Mohs JM, Kaplan SL, et al:: Evidence for parathyroid failure in magnesium deficiency. Science. 1972; 177(4049): 606-8. PubMed Abstract | Publisher Full Text

10. Perazella MA: Proton pump inhibitors and hypomagnesemia: a rare but serious complication. Kidney Int. 2013; 83(4): 553-6. PubMed Abstract | Publisher Full Text

11. Faroogi AA, Javeed MK, Javed Z, et al:: TRPM channels: same ballpark, different players, and different rules in immunogenetics. Immunogenetics. 2011; 63(12): 773-87.

PubMed Abstract | Publisher Full Text

12. Schlingmann KP, Weber S, Peters M, et al:: Hypomagnesemia with secondary hypocalcemia is caused by mutations in TRPM6, a new member of the TRPM gene family. Nat Genet. 2002; 31(2): 166-70. PubMed Abstract | Publisher Full Text

13. Woudenberg-Vrenken TE, Sukinta A, van der Kemp AW, et al:: Transient receptor potential melastatin 6 knockout mice are lethal whereas heterozygous deletion results in mild hypomagnesemia. Nephron Physiol. 2011; 117(2): p11-9. PubMed Abstract | Publisher Full Text

14. Chubanov V, Waldegger S, Mederos y Schnitzler M, et al:: Disruption of TRPM6/TRPM7 complex formation by a mutation in the TRPM6 gene cause hypomagnesemia with secondary hypocalcemia. Proc Natl Acad Sci U S A. 2004; 101(9): 2894-9.

PubMed Abstract | Publisher Full Text | Free Full Text

15. Chubanov V, Schlingmann KP, Waring J, et al:: Hypomagnesemia with secondary hypocalcemia due to a missense mutation in the putative pore-forming region of TRPM6. J Biol Chem. 2007; 282(10): 7656-67.

PubMed Abstract | Publisher Full Text

16. Jalkanen $\mathrm{R}$, Pronicka $\mathrm{E}$, Tyynismaa $\mathrm{H}$, et al:: Genetic background of $\mathrm{HSH}$ in three Polish families and a patient with an X;9 translocation. Eur J Hum Genet. 2006; 14(1): 55-62.

PubMed Abstract | Publisher Full Text

17. Huang $\mathrm{Y}$, Winkler PA, Sun W, et al:: Architecture of the TRPM2 channel and its activation mechanism by ADP-ribose and calcium. Nature. 2018; 562(7725): 145-9.

PubMed Abstract | Publisher Full Text

18. Wang L, Fu TM, Zhou Y, et al.: Structures and gating mechanism of human TRPM2. Science. 2018; 362(6421): pii: eaav4809. PubMed Abstract | Publisher Full Text | Free Full Text

19. Zhang Z, Toth B, Szollosi A, et al.: Structure of a TRPM2 channel in complex with $\mathrm{Ca}^{+}$explains unique gating regulation. eLife. 2018; 7: pii: e36409. PubMed Abstract | Publisher Full Text | Free Full Text

20. Autzen HE, Myasnikov AG, Campbell MG, et al:: Structure of the human TRPM4 ion channel in a lipid nanodisc. Science. 2018; 359(6372): 228-32. PubMed Abstract | Publisher Full Text | Free Full Text

21. Guo J, She J, Zeng W, et al.: Structures of the calcium-activated, non-selective cation channel TRPM4. Nature. 2017; 552(7684): 205-9. PubMed Abstract | Publisher Full Text | Free Full Text

22. Duan J, Li Z, Li J, et al.: Structure of full-length human TRPM4. Proc Natl Acad Sci U S A. 2018; 115(10): 2377-82.

PubMed Abstract | Publisher Full Text | Free Full Text

23. Winkler PA, Huang $\mathrm{Y}$, Sun W, et al:: Electron cryo-microscopy structure of a human TRPM4 channel. Nature. 2017; 552(7684): 200-4.

PublMed Abstract | Publisher Full Text

24. Duan J, Li Z, Li J, et al.: Structure of the mammalian TRPM7, a magnesium channel required during embryonic development. Proc Natl Acad Sci U S A. 2018; 115(35): E8201-e10.

PubMed Abstract | Publisher Full Text | Free Full Text

25. Yin $\mathrm{Y}, \mathrm{Wu} \mathrm{M}$, Zubcevic L, et al:: Structure of the cold- and menthol-sensing ion channel TRPM8. Science. 2018; 359(6372): 237-41. PubMed Abstract | Publisher Full Text | Free Full Text

26. Sayer J: Alignment of human TRPM channels 1-8 amino acid sequences. figshare. Figure. 2019.

27. Xie J, Sun B, Du J, et al:: Phosphatidylinositol 4,5-bisphosphate $\left(\mathrm{PIP}_{2}\right)$ controls magnesium gatekeeper TRPM6 activity. Sci Rep. 2011; 1: 146. PubMed Abstract | Publisher Full Text | Free Full Text

28. Rohács $\mathrm{T}$, Lopes $\mathrm{CM}$, Michailidis I, et al:: $\mathrm{PI}(4,5) \mathrm{P}_{2}$ regulates the activation and desensitization of TRPM8 channels through the TRP domain. Nat Neurosci. 2005; 8(5): 626-34

PubMed Abstract | Publisher Full Text

29. Nilius B, Mahieu F, Prenen J, et al.: The Ca2+-activated cation channel TRPM4 is regulated by phosphatidylinositol 4,5-biphosphate. EMBO J. 2006; 25(3): 467-78.

PubMed Abstract | Publisher Full Text | Free Full Text

30. Yamaguchi S, Tanimoto A, Otsuguro K, et al:: Negatively charged amino acids near and in transient receptor potential (TRP) domain of TRPM4 channel are one determinant of its $\mathrm{Ca}^{+}$sensitivity. J Biol Chem. 2014; 289(51): 35265-82.

PubMed Abstract | Publisher Full Text | Free Full Text

31. Bertamino A, Ostacolo C, Ambrosino P, et al.: Tryptamine-Based Derivatives as Transient Receptor Potential Melastatin Type 8 (TRPM8) Channel Modulators. J Med Chem. 2016; 59(5): 2179-91.

PubMed Abstract | Publisher Full Text

32. McKenna A, Hanna M, Banks E, et al.: The Genome Analysis Toolkit: a MapReduce framework for analyzing next-generation DNA sequencing data. Genome Res. 2010; 20(9): 1297-303. PubMed Abstract | Publisher Full Text | Free Full Text

33. Soding J: Protein homology detection by HMM-HMM comparison. Bioinformatics. 2005; 21(7): 951-60. PubMed Abstract | Publisher Full Text

34. Sali A, Blundell TL: Comparative protein modelling by satisfaction of spatial restraints. J Mol Biol. 1993; 234(3): 779-815.

PubMed Abstract | Publisher Full Text

35. Yang J, Yan R, Roy A, et al:: The I-TASSER Suite: protein structure and function prediction. Nat Methods. 2015; 12(1): 7-8.

PubMed Abstract | Publisher Full Text | Free Full Text 


\section{Open Peer Review}

\section{Current Peer Review Status:}

\section{Version 1}

Reviewer Report 09 August 2019

https://doi.org/10.5256/f1000research.20831.r48695

(C) 2019 Zhu N. This is an open access peer review report distributed under the terms of the Creative Commons Attribution License, which permits unrestricted use, distribution, and reproduction in any medium, provided the original work is properly cited.

\section{Na Zhu}

Department of Systems Biology, Columbia University Medical Center, Columbia, USA

The authors identified that a novel deleterious missense variant is causal to hypomagnesemia. They found this variant from a pediatric patient in consanguineous family. Both parents are heterozyous carriers while the patient is homozygoty carrier. They inferred the pathogenicity of this variant using in silico method.

This variant is never seen in any large population datasets, it is predicted to be deleterious using various prediction tools. This variant is also indicated disrupting stabilising TRP domain from the protein structure analysis tool. The call is also verified to be true using chromatogram. Most importantly, TRPM6 has been reported to be associated with hypomagnesemia. Therefore, I agree with the authors conclusion, this variant is a causal variant to this patient.

Is the background of the case's history and progression described in sufficient detail? Yes

Are enough details provided of any physical examination and diagnostic tests, treatment given and outcomes?

Yes

Is sufficient discussion included of the importance of the findings and their relevance to future understanding of disease processes, diagnosis or treatment? Yes

Is the case presented with sufficient detail to be useful for other practitioners? Yes

Competing Interests: No competing interests were disclosed.

Reviewer Expertise: statistical study on human genetics 


\title{
I confirm that I have read this submission and believe that I have an appropriate level of expertise to confirm that it is of an acceptable scientific standard.
}

Reviewer Report 15 July 2019

https://doi.org/10.5256/f1000research.20831.r50544

(C) 2019 Dixit A. This is an open access peer review report distributed under the terms of the Creative Commons Attribution License, which permits unrestricted use, distribution, and reproduction in any medium, provided the original work is properly cited.

\begin{abstract}
Abhijit Dixit
Department of Clinical Genetics, Nottingham University Hospitals NHS Trust, Nottingham, UK

In this manuscript, Jamie Willows and colleagues describe the genetic diagnosis of hypomagnesemia with secondary hypocalcemia (HSH) in a consanguineous family, with identification of a novel homozygous TRPM 6 missense variant in the proband. The authors have done a good job of placing this rare condition in the context of wider genetic and acquired causes of hypomagnesemia. There is a fair degree of detail in terms of the clinical course and investigations - see comments below for suggested changes.
\end{abstract}

The identification of a missense variant is noteworthy. The authors do not highlight the fact that the vast majority of previously reported TRPM6 mutations result in loss-of-function of the protein. Only a small number of missense mutations have been reported and still fewer have had functional assessment - still showing loss of TRPM6 channel function (Lainez et al., 2014 ${ }^{1}$ ). Functional studies are, however, not easy to undertake and the authors have provided evidence supporting pathogenicity of the novel variant in their family using protein modelling.

The most interesting and possibly contentious issue is the identification of neonatal hypomagnesemia in the siblings with heterozygous p.Lys1098Glu variant. My understanding from the literature is that even asymptomatic hypomagnesemia has not been documented in adult carriers of TRPM 6 mutations, and therefore symptomatic presentation would be very unusual indeed. The authors attribute the hypomagnesemia in the heterozygous siblings to immaturity of the DCT. The following points, in my view, merit some extra thought:

1. The only serum magnesium value provided for the sibling II: 2 is $0.53 \mathrm{mmol} / \mathrm{L}$ in the context of 'abnormal eye movements.' The complex partial seizure is not described and no further definite seizure episode is documented. Is it possible to be certain that this episode represented a symptomatic seizure and suggest a causal relationship with modest hypomagnesemia? Were other investigations (e.g. MRI brain, blood sugar etc.) performed to identify an alternative explanation for the child's paroxysmal episode?

2. Information on magnesium levels in the parents would be very important and, if possible, maternal magnesium levels around the time of delivery.

3. It is not specified for how long the magnesium supplementation was prescribed in the two children. 
4. It would be helpful to clarify the timeline of events further. Before exome sequencing revealed the diagnosis, what were the possible diagnostic considerations in the two older siblings?

Lastly, some minor changes would further improve the manuscript:

1. Three letter amino acid nomenclature is preferable to the single letter codes now, i.e. Lys1098Glu instead of K1098E.

2. In Table 1, the current magnesium levels of patient II:1 has a decimal point missing. '0.4$0.6 \mathrm{mmol} / \mathrm{L}^{\prime}$ is presumably what was intended.

3. It is preferable to say 'second cousins' rather than 'second-degree cousins', as family relationships in degree terms implies parents/siblings and children as first degree relatives and uncles/grandparents as second degree relatives. First cousins would be third degree relatives. Ideally, a proper pedigree should be drawn so that the familial relationship is clear.

\section{References}

1. Lainez S, Schlingmann KP, van der Wijst J, Dworniczak B, et al.: New TRPM6 missense mutations linked to hypomagnesemia with secondary hypocalcemia.Eur J Hum Genet. 2014; 22 (4): 497-504 PubMed Abstract | Publisher Full Text

Is the background of the case's history and progression described in sufficient detail? Partly

Are enough details provided of any physical examination and diagnostic tests, treatment given and outcomes?

Partly

Is sufficient discussion included of the importance of the findings and their relevance to future understanding of disease processes, diagnosis or treatment?

Partly

Is the case presented with sufficient detail to be useful for other practitioners? Yes

Competing Interests: No competing interests were disclosed.

Reviewer Expertise: Renal and neurological genetic disorders. Dysmorphology. Disorders of sex development.

I confirm that I have read this submission and believe that I have an appropriate level of expertise to confirm that it is of an acceptable scientific standard, however I have significant reservations, as outlined above. 
Reviewer Report 03 July 2019

https://doi.org/10.5256/f1000research.20831.r50062

(c) 2019 Romdhane L. This is an open access peer review report distributed under the terms of the Creative Commons Attribution License, which permits unrestricted use, distribution, and reproduction in any medium, provided the original work is properly cited.

\author{
Lilia Romdhane \\ ${ }^{1}$ Laboratory of Biomedical Genomics and Oncogenetics, Pasteur Institute of Tunis, University of \\ Tunis El Manar, Tunis, Tunisia \\ 2 Faculty of Sciences, Bizerte, University of Carthage, Zarzouna, Tunisia
}

The authors provide a molecular investigation of a familial hypomagnesaemia using whole exome sequencing in a consanguineous family from Oman. A novel missense mutation in the TRPM6 gene at homozygous state has been identified in the index patient. A bioinformatic analysis using a modelling approach was performed to explain the pathogenic effect of the novel mutation.

\title{
General comments:
}

The authors have to provide the OMIM numbers of the diseases reported in the manuscript. The version of the human genome used for read alignment and annotation also has to be mentioned. The status of the identified mutation "novel or new" is only provided in the abstract and the conclusion. Is this family the first one reported with the disease from Oman? The result section drastically lacks details. In addition, details on the methods and tools used during this study have to be provided. Please divide the "Methods" section into sub-sections: Example: Whole Exome Sequencing, WES data analysis, Homozygosity mapping, TRMP6 ortholog alignment, Structural modelling ...

\section{Specific comments:}

Question: Are enough details provided of any physical examination and diagnostic tests, treatment given and outcomes?

Reviwer's comment: Clinical description of the parents are lacking as it is mandatory to explain why heterozygous siblings show a moderate phenotype and therefore, helps the interpretation of the genetic results. Are the parents also showing abnormal level of magnesium ?

Question: Is sufficient discussion included of the importance of the findings and their relevance to future understanding of disease processes, diagnosis or treatment?

Reviwer's comment: Familial hypomagnesaemia (OMIM\#602014) is a genetic autosomal recessive disorder caused by mutations in the TRPM6 gene in homozygous or compound heterozygous state. The authors identified a novel missense mutation at homozygous state in the index patient. The parents and the sister and brother were heterozygous. In the absence of the precise clinical description of the parents, the finding of the expression of some clinical symptoms in the brother and sister harboring the mutation at the heterozygous state is not consistent with the autosomal recessive transmission mode of the disease. Therefore, are the parents completely 
healthy or are they showing some hypomagnesaemia? The authors state that no adults heterozygous for TRPM6 mutations have been reported showing abnormal serum magnesium levels. Is this statement supported by any biochemical dosages in the parents of the studied family? As heteroygous carriers with moderate expression of an autosomal recessive disease have been reported in a consanguineous population (Mokni et $\mathrm{al}^{1}$ ) the authors have to provide further clinical details of the parents and reformulate their hypothesis.

Moreover, as the authors performed a whole exome sequencing, they have access to the completed catalogue of coding variants of the patient. Is the patient harboring other variants of functional effects in the TRPM6 gene and/other candidate genes? in modifier genes? Are these variants present in the brother and sister that help explaining their phenotypes? Lainez et al ${ }^{2}$, reported a patient with a TRPM6 heterozygous mutation with familial hypomagnesaemia. They explained the phenotype by the presence of a variant, that when combined with the pathogenic mutation, drastically decreases the magnesium level. They supported they statement with functional assay. Therefore, the authors are invited to perform again the bioinformatic analysis of variant annotation and filtering. Consequently, both the result and discussion sections have to be revised.

\section{References}

1. Mokni M, Charfeddine C, Ben Mously R, Baccouche D, et al.: Heterozygous manifestations in female carriers of Mal de Meleda.Clin Genet. 2004; 65 (3): 244-6 PubMed Abstract

2. Lainez S, Schlingmann KP, van der Wijst J, Dworniczak B, et al.: New TRPM6 missense mutations linked to hypomagnesemia with secondary hypocalcemia.Eur J Hum Genet. 2014; 22 (4): 497-504 PubMed Abstract | Publisher Full Text

Is the background of the case's history and progression described in sufficient detail? Yes

Are enough details provided of any physical examination and diagnostic tests, treatment given and outcomes?

Partly

Is sufficient discussion included of the importance of the findings and their relevance to future understanding of disease processes, diagnosis or treatment?

Partly

Is the case presented with sufficient detail to be useful for other practitioners? Partly

Competing Interests: No competing interests were disclosed.

Reviewer Expertise: Rare genetic diseases, consanguinity, NGS data analysis, bioinformatics

I confirm that I have read this submission and believe that I have an appropriate level of expertise to confirm that it is of an acceptable scientific standard, however I have significant reservations, as outlined above. 
Reviewer Report 24 June 2019

https://doi.org/10.5256/f1000research.20831.r48551

(C) 2019 Schlingmann K. This is an open access peer review report distributed under the terms of the Creative Commons Attribution License, which permits unrestricted use, distribution, and reproduction in any medium, provided the original work is properly cited.

\section{Karl Peter Schlingmann}

Department of General Pediatrics, University Children's Hospital, Münster, Germany

Dear editors and authors,

In their manuscript entitled "Investigation and molecular genetic diagnosis of familial

hypomagnesemia: a case report" Jamie Willows and colleagues describe a patient with the typical clinical presentation of familial hypomagnesemia with secondary hypocalcemia (HSH). Molecular genetic studies identified a homozygous mutation in the TRPM6 gene as the underlying pathology. The TRPM 6 gene encodes a member of the transient receptor potential (TRP) family of ion channels that is involved in the formation of epithelial magnesium permeable ion channels in intestine and kidney. If it does so alone or in cooperation with TRPM7 has been a matter of debate.

In addition to the initial studies and two larger follow-up reports, 1, 2, 3, 4 mostly small case series or case reports have been published of patients with $\mathrm{HSH}$ and mutations in TRPM6. HSH is thought to represent a classic autosomal-recessive disease with unaffected heterozygous parents and siblings. Most patients were found to carry non-sense mutations in TRPM6 including stop mutations, small deletions/insertions, leading to a shift in the reading frame and premature stops of translations, splice site mutations, and also deletions of larger parts of the gene. Only a small number of missense mutations have been reported of which a subset has been analyzed functionally. 4, 5, 6 These almost uniformly lead to a complete loss-of-function.

Study design and results of this report are presented accurately and the appropriate literature is cited correctly. The methods used for molecular diagnosis and in-silico modeling of the identified mutant are provided. The initial presentations as well as diagnostic tests performed, treatments given and clinical outcomes of the index patient and siblings are described in sufficient detail. In the context of the published literature, this case report is unique for two reasons: to my knowledge, the discovered p.K1098E variant is the first missense mutation directly affecting the TRP domain of the TRPM6 ion channel subunit. The TRP domain is thought to play a crucial role in ion channel multimerization as well as in channel activation by PIP2 (phosphatidylinositol-4,5-bisphosphate). Accordingly, the authors present comprehensive data analyzing the putative effects of the discovered mutant by comparing this naturally occurring mutant to engineered mutants at the identical position in TRPM6 and related TRPM channel subunits. Though the effects of engineered mutants on channel activity as well as PIP2 mediated channel activation are not consistent, the genetic data presented here together with the disease phenotype clearly argue for the pathogenetic role of the discovered mutant. It will be interesting to study this mutant functionally in an overexpression system (especially in combination with wildtype TRPM6 subunits and TRPM7, see below). The second intriguing finding presented here is that, in addition to the index patient, two siblings carrying the p.K1098E variant in heterozygous state presented in infancy with hypomagnesemia and a cerebral seizure in case of one sibling. Such a finding in heterozygous mutation carriers has not been reported before. The authors consider this finding a general 
feature of the disease and attribute it to a possible immaturity of the renal tubule in early life. Serum magnesium levels have not been systematically evaluated in clinically unaffected siblings so far. However, measurements of serum magnesium levels in the first weeks of life have been advocated in siblings to exclude disease before clinical presentation with cerebral seizures and before quick genetic testing became feasible. Newborns usually start with their mothers serum magnesium at birth and in case of defective TRPM6 show a continuous decline of serum levels over the following weeks. At least in single families, measurement of serum magnesium yielded normal levels and was able to exclude disease in younger siblings (unpublished data, personal observation). Therefore, the information on maternal serum magnesium is critical in this family to better classify the observed changes in the heterozygous siblings as following the mentioned approach, the measurement of serum magnesium levels would have suggested the diagnosis of $\mathrm{HSH}$ also in the heterozygous siblings of this family rather than excluding classic disease. Finally, it is also conceivable that the hypomagnesemia observed in the siblings of the family presented here represents a mutation specific phenomenon rather than a general finding in patients with heterozygous TRPM6 mutations which could also be discussed in the report. Are there indications of a functional effect of the p.K1098E mutant on heteromultimerization with wildtype TRPM6 or TRPM7 via TRP domain interactions? Were there additional variants in the TRPM6 gene identified by WES (especially on the unaffected alleles of siblings)? Do the two siblings share the identical unaffected allele of mother or father? Could an additional variant potentially explain the transient phenotype?

Minor comments and suggestions:

the dose of daily oral magnesium should please be provided in $\mathrm{mmol} / \mathrm{kg} / \mathrm{day}$ as it allows easier comparison with published doses (500 mg Mg-sulphate should be $4.06 \mathrm{mmoles}$ ) discussion line 7: "need" instead of "needs" (serum levels)

could you please add a citation for the physiological summary in the first discussion section (maybe Dai \& Quamme, Phys Rev 2001? ${ }^{7}$ )

page 6, second paragraph: FXYD2 instead of FYXD2, CNNM2 instead of CNMM2.

page 6, second paragraph: I am not aware of inherited EGFR mutations?!

page 6, second paragraph: ATP1A1 could be added.

page 6 , second paragraph: the possibility of de-novo mutational events (in addition to recessive and dominant) should be mentioned (especially for ATP1A1 and CNNM2).

please provide OMIM number and nomenclature for $\mathrm{HSH}$.

page 6, third paragraph: patients typically present in the neonatal period and in infancy (ranging from a couple of days to $\sim 8$ months, rarely later)

\section{References}

1. Schlingmann KP, Weber S, Peters M, Niemann Nejsum L, et al.: Hypomagnesemia with secondary hypocalcemia is caused by mutations in TRPM6, a new member of the TRPM gene family.Nat Genet. 2002; 31 (2): 166-70 PubMed Abstract | Publisher Full Text

2. Walder RY, Landau D, Meyer P, Shalev H, et al.: Mutation of TRPM6 causes familial hypomagnesemia with secondary hypocalcemia.Nat Genet. 2002; 31 (2): 171-4 PubMed Abstract | Publisher Full Text

3. Schlingmann KP, Sassen MC, Weber S, Pechmann U, et al.: Novel TRPM6 mutations in 21 families with primary hypomagnesemia and secondary hypocalcemia.J Am Soc Nephrol. 2005; 16 (10): 3061 9 PubMed Abstract | Publisher Full Text 
4. Lainez S, Schlingmann KP, van der Wijst J, Dworniczak B, et al.: New TRPM6 missense mutations linked to hypomagnesemia with secondary hypocalcemia.Eur J Hum Genet. 2014; 22 (4): 497-504 PubMed Abstract | Publisher Full Text

5. Chubanov V, Waldegger S, Mederos y Schnitzler M, Vitzthum $H$, et al.: Disruption of TRPM6/TRPM7 complex formation by a mutation in the TRPM6 gene causes hypomagnesemia with secondary hypocalcemia.Proc Natl Acad Sci U S A. 2004; 101 (9): 2894-9 PubMed Abstract I Publisher Full Text

6. Chubanov V, Schlingmann KP, Wäring J, Heinzinger J, et al.: Hypomagnesemia with secondary hypocalcemia due to a missense mutation in the putative pore-forming region of TRPM6.J Biol Chem. 2007; 282 (10): 7656-67 PubMed Abstract | Publisher Full Text

7. Dai LJ, Ritchie G, Kerstan D, Kang HS, et al.: Magnesium transport in the renal distal convoluted tubule.Physiol Rev. 2001; 81 (1): 51-84 PubMed Abstract | Publisher Full Text

Is the background of the case's history and progression described in sufficient detail? Yes

Are enough details provided of any physical examination and diagnostic tests, treatment given and outcomes?

Yes

Is sufficient discussion included of the importance of the findings and their relevance to future understanding of disease processes, diagnosis or treatment?

Partly

Is the case presented with sufficient detail to be useful for other practitioners?

Partly

Competing Interests: No competing interests were disclosed.

Reviewer Expertise: Molecular genetics of hereditary disorders of electrolyte metabolism.

I confirm that I have read this submission and believe that I have an appropriate level of expertise to confirm that it is of an acceptable scientific standard, however I have significant reservations, as outlined above. 
The benefits of publishing with F1000Research:

- Your article is published within days, with no editorial bias

- You can publish traditional articles, null/negative results, case reports, data notes and more

- The peer review process is transparent and collaborative

- Your article is indexed in PubMed after passing peer review

- Dedicated customer support at every stage

For pre-submission enquiries, contact research@f1000.com 